Arkas Hasanah $^{1}$

Elise Muryanti ${ }^{2}$

\section{Pengaruh Penggunaan Media Diorama terhadap Perkembangan Kemampuan Motorik Halus Anak Usia Dini}

\begin{abstract}
Abstrak
Penelitian ini memiliki tujuan untuk mengetahui seberapa pengaruh dari penggunaan media diorama terhadap perkembangan kemampuan motorik halus anak di TK Jannatul Ma'wa Padang. Dalam penelitian ini menggunakan metode penelitian kuantitatif yang berbentuk quasy eksperimen. Dengan jumlah populasi anak TK Jannatul Ma'wa Padang sebanyak 20 orang. Kelas B1 dijadikan sebagai sampel kelas eksperimen, kelas B2 dijadikan sebagai kelas kontrol, masing-masing kelas berjumlah 10 orang anak. Tes dijadikan sebagai teknik pengumpulan data, data yang didapat kemudian diolah menggunakan uji-t untuk melihat perbandingan. Dari hasil penelitian yang didapat menunjukkan rata-rata dari nilai kelas eksperimen adalah 60,25, sedangkan rata-rata nilai kelas kontrol adalah 53,75. Sehingga dapat disimpulkan bahwa penggunaan media diorama berpengaruh dalam perkembangan kemampuan motorik halus anak.
\end{abstract}

Kata kunci : media diorama, kemampuan motorik halus, anak usia dini

\begin{abstract}
This study aims to determine how the influence of diorama usage on the development of fine motor skills of children in kindergarten jannatul ma'wa padang. In this study using quantitative research methods in the form of quasy eskperiments. With a total population of 20 kindergarten childrens jannatul ma'wa padang. Class B1 used as the experimental class, class B2 used as the control class, each class consists of 10 children. Test are used as data collection techniques, the data can then be processed using the t-test to see the comparation. So it can be concluded that the use of diorama media influences the development of children's fine motor skills.
\end{abstract}

Keyword : diorama media, fine motor skills, early childhood

\title{
PENDAHULUAN
}

Pendidikan adalah termasuk salah satu kebutuhan hidup yang paling mendasar di zaman globalisasi seperti sekarang ini, dengan adanya pendidikan bisa mengubah nasib hidup seseorang. Pendidikan juga menjadi tolak ukur tingkat hidup kesejahteraan manusia di zaman internet sekarang. Pendidikan bisa di dapatkan dari PAUD sampai perkuliahan. Anak usia dini ialah anak yang berumur dari nol sampai delapan tahun, anak usia dini juga termasuk individu yang unik, kenapa disebut unik ya karena mereka dilahirkan dengan memiliki minat, bakat dan potensi yang berbeda yang diberikan oleh Allas Swt, bahkan anak yang terlahir kembar saja memiliki tingkat kemampuan dan

\footnotetext{
${ }^{1}$ Pendidikan Guru Pendidikan Anak Usia Dini, Universitas Negeri Padang Email : arkas150397@gmail.com

${ }^{2}$ Pendidikan Guru Pendidikan Anak Usia Dini, Universitas Negeri Padang

Email : elisemuryanti@yahoo.com
} 
intelegensi yang berbeda, maka dari itu guru dan orang tua bisa memahamai perbedaan bakat,minat \& potensi yang dimiliki oleh anak.

Supaya anak bisa tumbuh \& kembang dengan optimal, jadi sebaiknya anak menempuh PAUD. Apa itu pendidikan anak usia dini atau sering kita dengar dengan istilah PAUD? Nah, PAUD adalah upaya pemberian stimulasi yang diberikan kepada anak yang berusia dari nol hingga delapan 8 tahun. Mansur (2014: 88-89) juga menjelaskan tentang PAUD yaitu sebuah keberlangsungan pembinaan yang diperuntukkan kepada anak berusia nol sampai enam tahun secara komplek dan didalam mencangkup semua aspek, juga memberikan stimulasi bagi perkembangan jasmani dan rohani, motorik, akal pikiran, emosional dan sosial agar anak bisa tumbuh dan berkembang dengan optimal. Di Indonesia kita bisa mendapatkan jenis layanan PAUD berdasarkan usia anak yaitu layanan PAUD yang pertama ialah Taman penitipan anak (TPA) untuk anak berusia dari tiga bulan- dua tahun, kemudian Kelompok bermain (KB) yaitu layanan yang diberikan kepada anak yang berusia dua tahun sampai empat tahun, layanan selanjutnya ialah Taman kanak-kanak atau TK ialah layanan yang diberikan kepada anak yang berumur 5-6 tahun.

Anak usia dini ini memiliki ragam aspek perkembangan diantaranya ada aspek kognitif, fisik motorik,sosial emosional seni, , nilai agama moral dan bahasa. Semua aspek tersebut sangat penting dan perlu adanya stimulasi yang dilakukan kepada anak agar berkembang optimal sesuai usia nya. aspek yang tak kalah penting dan harus distimulasi yaitu aspek perkembangan motorik halus, dimana dengan adanya kemampuan motorik halus ini membantu dan memudahkan anak dalam kehidupannya, bayangkan saja jika anak tidak memilki kemampuan motorik halus maka anak tidak akan bisa menggengam sesuatu, melempar sesuatu dan memegang sesuatu.

Motorik halus adalah keterampilan otot-otot yang dimiliki oleh anak seperti mengancingkan baju, menulis, menggengam dimana kegiatannya tidak memerlukan banyak tenaga namun memerlukan koordinasi yang tepat. Menurut Permendikbud No 137 tahun 2014 menyatakan bahwa kemampuan motorik halus mencangkup keluesan jari jemari dan alat dalam mengekpresikan juga mengekplorasi diri dalam berbagai bentuk. Motorik halus juga termasuk sebuah gerakan yang dilakukan hanya oleh bagian-bagian tubuh tertentu juga tidak memerlukan kemampuan otot yang terlalu besar namun memerlukan koordinasi yang tepat antara mata dan tangan. Gerakan motorik halus yang terdapat pada anak berkaitan dengan kegiatan memegang atau meletakkan suatu objek menggunakan jari jemari tangan. Kegiatan yang dapt mengembangkan kemampuan motorik halus anak sangatlah banyak. Salah satu nya ialah penggunaan media diorama.

Adapun pengertian media yaitu sebuah salah satu sarana penunjang pembelajaran di dalam kelas dimana dengan adanya media ini memudahkan anak dan guru dalam proses pembelajaran di kelas. Gerlach dalam sanjaya juga menjelaskan tentang pengertian media yaitu semua unsur yang mampu menciptakan kondisi dimana siswa bisa memperoleh sikap, pengetahuan dan keterampilan. Media yang digunakan guru haruslah bervariasi dan unik agar memberikan pengaruh dimana anak menjadi tertarik dan fokus ketika pembelajaran sedang berlangsung. Media yang digunakan guru tidak la harus mahal, bisa menggunakan benda-benda bekas atau yang tidak perpakai yang ada 
di sekitar kita, dengan syarat media yang kita buat aman dan tidak beracun. Media ini terdiri dari beberapa macam. media visual yang bisa digunakan yaitu menggunakan media diorama.

Media diorama termasuk kedalam salah satu media 3 dimensi atau sering kita kenal dengan istilah media serba aneka. Daryanto dalam Murtiana media diorama ialah sebuah media tanpa adanya proyeksi yang diberikan secara visual tiga dimensional berwujud sebagai duplikat yang mewakili rupanya. Kustandi dan Sutjipto dalam Iswandari (2017) juga menjelaskan tentang media diorama ialah sebuah penyuguhan pemandangan indah 3 dimensi kecil yang dibuat untuk memberikan penggambaran asli dari sebuah pemandangan yang seseungguhnya.

\section{METODE PENELITIAN}

Penelitian ini termasuk kedalam bentuk penelitian kuantitatif dengan jenis quasy ekspeiment atau eksperiment semu. Yang dijadikan populasi di penelitian ini adalah anak TK Jannatul Ma'wa Padang. Teknik sampling jenuh yang digunakan dalam teknik pengambilan sampel. Dimana teknik sampling jenuh ini digunakan ketika bila sampel tidak terlalu banyak dan semua anggota populasi dijadikan untuk sampel. Berdasarkan pengertian diatas kelas yang menjadi sampel dalam penelitian ini yaitu kelas B 1 \& B 2, dimana setiap kelas berjumlah 10 orang.

Format checklist merupakan instrument penilaian yang digunakan dalam penelitian ini. Kurikulum 2013 (2015: 17) menjelaskan bahwa penilaian dimulai dari gradasi positif sampai dengan negatif. Skor 4 diberikan jika anak berkembang sangat baik (BSB), skor 3 diberikan jika anak berkembang sesuai harapan (BSH), skor 2 diberikan kepada anak jika anak mulai berkembang (MB) dan skor 1 diberikan kepada anak jika anak belum berkembang (BB).

Arikunto (2014) menyatakan validitas ialah sebuah tolak ukur yang digunakan untuk menguji keabsahan atau kevalidan sebuah instrument. Instrument dikatakan valid apabila memiliki nilai yang tinggi, juga ketika nilai yang rendah maka instrument tersebut dapat dikatakan tidak valid.

Arikunto (2014) menyatakan reliabilitas adalah sebuah instrument yang cukup bisa dipercaya bisa dipakai sebagai alat pengumpulan data dikarenakan instrument tersebut benar. Rumus Alpha merupakan rumus yang dipakai dalam reliabilitas instrument. Membandingkan nilai rata-rata antara kelas eksperiment dan kelas kontrol merupakan teknik analisis data yang digunakan dalam penelitian ini, sehingga dibuktikan dengan uji-t ( $\mathrm{t}$ test). Uji normalitas dan uji homogenitas perlu dilakukan sebelum uji t.

Untuk melihat sampel yang digunakan berdistribusi normal atau tidaknya perlu dilakukan uji normalitas terlebih dahulu. Untuk melihat data bersifat normal bisa dengan melakukan uji liliefors. Jika data sudah didapatkan berdistribusi normal dan bersifat homogen maka bisa dilanjutkan analisis data berdasarkan tekhnik analisis data yang sudah ditentukan dengan mencari perbandingan dengan melakukan uji t.

\section{HASIL DAN PEMBAHASAN}


Data hasil pretest kemampuan motorik halus anak dikedua kelas diolah untuk melakukan uji normalitas. Uji liliefors merupakan teknik analisis data yang digunakan pada uji normalitas. Analisis normalitas kelas eksperiment juga kontrol.

Dari hasil uji normalitas di kelas eksperiment dan kontrol didapatkan harga $\mathrm{L}_{\mathrm{o}}$ dan $\mathrm{L}_{\mathrm{t}}$ pada taraf nyata $(0,05)$ untuk $(\mathrm{N})=10$.

Tabel (1) : uji normalitas kelas eksperiment dan kontrol

\begin{tabular}{lllllll}
\hline No & Kelas & $(\mathrm{N})$ & $(\mathrm{A})$ & $\mathrm{L}_{\mathrm{o}}$ & $\mathrm{L}_{\mathrm{t}}$ & ket \\
\hline 1 & eksperiment & $(10)$ & 0,05 & 0.1739 & 0.2580 & Normal \\
2 & Control & $(10)$ & 0,05 & 0.2451 & 0.2580 & Normal \\
\hline
\end{tabular}

Sesuai dengan tebel 1. nampak kelas eksperiment nilai $\mathrm{L}_{\text {hitung }} 0.1739<$ dari pada $\mathrm{L}_{\text {tabel }} 0.2580$ untuk a 0.05 . Oleh sebab itu nilai kelas eksperiment dari data yang bersifat normal. Kelas kontrol diperoleh $\mathrm{L}_{\text {hitung }}<$ dari $\mathrm{L}_{\text {tabel }} 0.2580$ untuk a 0.05. dapat dikatakan kelas ini juga beasal dari data berdistribusi normal.

Pengujian homogenitas merupakan pengujian kedua dengan memakai rumus Fhitung. Adapun tujuan dari penghitungan ini agar mengetahui apakah data tersebut dari kelas yang homogeny, antara kelas eksperiment dan kontrol. Menggunakan derajat kebebasan (N1-1), (N2-1) dan taraf signifikansi 0.05 pada tabel berdistribusi $F$ terbaca batas signifikan (Ftabel) adalah 3.18. mengingat Fhitung lebih kecil dari Ftabel, maka bisa disimpulkan kedua varian bersifat homogeny. Dengan kata lain kedua kelompok sampel tersebut berasal dari populasi yang homogeny.

Sesudah melakukan uji normalitas dan uji homogenitas, bisa diketahui bahwa kelas eksperiment dan kontrol bersifat normal juga mempunyai varians yang homogeny. Maka dari itu bisa disambung dengan melakukan pengujian hipotesis menggunkan tekhnik t -test.

Jika Thitung > Ttabel maka $\mathrm{H}_{\mathrm{o}}$ ditolak dan $\mathrm{H}_{\mathrm{a}}$ diterima

Jka Thitung > Ttabel maka $\mathrm{H}_{\mathrm{o}}$ diterima dan $\mathrm{H}_{\mathrm{a}}$ ditolakk

Dibawah ini adalah gambaran penggolahan data dengan $\mathrm{t}$ tes.

$$
\begin{gathered}
t=\frac{\bar{X}_{A 1}-\bar{X}_{2}}{\sqrt{\frac{\sum D^{2} \frac{\left(\sum D\right)^{2}}{n}}{n(n-1)}}} \\
t=\frac{49.38-46.25}{\sqrt{\frac{195.31-\frac{(-31.25)^{2}}{10}}{10(10-1)}}} \\
t=\frac{3.13}{\sqrt{\frac{98}{90}}} \\
t=3
\end{gathered}
$$

Derajat kebebasan $(\mathrm{D} \mathrm{k})=\mathrm{N}-1=10-1=(9)$ 
Taraf signifikan $\mathrm{a}=0.05$

Dari hasil analisis diatas bisa dirangkum ada terdapat pengaruh yang signifikan antara kelas eksperiment terhadap kelas kontrol pada anak TK Jannatul Ma'wa Padang karena Thitung > Ttabel 3>1.83.

Nilai posttest dikelas eksperiment dan kontrol diolah untuk dijadikan dalam penentuan uji normalitas. Uji liliefors digunakan untuk menguji normalitas.

Tabel 2. Uji normalitas data posstest

\begin{tabular}{ccccc}
\hline Data & $\mathrm{N}$ & $\mathrm{L}_{\mathrm{o}}$ & $\mathrm{L}_{\mathrm{t}}$ & keterangan \\
\hline Tes akhir eskperiment & 10 & 0.1348 & 0.2580 & normal \\
Tes akhir konrol & 10 & 0.1370 & 0.2580 & normal \\
\hline
\end{tabular}

Terlihat kelas eksperiment memiliki nilai Lhitung $0.1348<$ dari pada Ltabel 0.2580 untuk $\mathrm{a}=0.05$ maka dikatakan nilai kelas eksperiment asalnya dari data berdistribusi normal. Uji homogenitas menggunakan Fhitung. (Uji homogenitas) bertujuan agar mengetahui apakah data tersebut asalnya dari kelas yang homogeny, antara kelas eksperiment dengan kelas kontrol.

$$
\text { Fhitung }=\frac{\text { varians besar }}{\text { varians kecil }}=\frac{131}{115}=1.14
$$

Dengan memakai derajat kebebasan (n-1) dan taraf signifikansi 0.05 pada tabel berdistribusi $\mathrm{F}$ dibaca batas signifikansi $\left(\mathrm{F}_{\text {tabel }}\right)$ adalah 3.18 mengingat Fhitung $>$ dari Ftabel. Bisa disimpulkan bahwa kedua varian homogeny.

Sesudah adanya uji normolitas dan uji homogeniitas, dapat diketahui bahwa kedua kelas sampel berdistribusi normal, mempunyai varians homogeny. Bisa disambung dengan melakukan uji hipotesis dengan teknik $t$ tes. Dibawah ini adalah gambaran pengolahan data menggunakan t- tes.

$$
\begin{array}{r}
=\frac{\bar{X}_{A 1}-\bar{X}_{2}}{\sqrt{\frac{\sum D^{2} \frac{\left(\sum D\right)^{2}}{n}}{n(n-1)}}} \\
t=\frac{60.63-53.75}{\sqrt{\frac{585.94-\frac{(-68.75)^{2}}{10}}{10(10-1)}}} \\
t=\frac{1.1}{\sqrt{\frac{2.9}{90}}} \\
t=6
\end{array}
$$

Derajat kebebasan $(\mathrm{d} \mathrm{k})=\mathrm{n}-1=10-1=9$

Tarafsignifikansi $\alpha=0.05$

$$
\mathrm{t}_{\text {tabel }}=1.83
$$

Terdapat pengaruh yang berbeda dari kelas eksperiment dengan kelas kontrol pada anak TK Jannatul Ma'wa Padang karena $t_{\text {hitung }}>t_{\text {tabel }}$ 6>1.83. Sesudah melakukan 
perhitungan nilai pretest dan posttest. Nilai tertinggi pretest didapatkan di kelas eksperiment sebanyak 62.5, kemudian nilai terendah sebanyak 37.5 dengan rata-rata 49.375. di kelas kontrol nilai tertinggi yang didapatkan adalah 56,25 kemudian nilai terendah sebanyak 37.5 dengan rata-rata 46.25. Pada hasil perhitungan Posstest didapatkan nilai tertinggi dikelas eksperiment sebanyak 75 dan nilai terendah dikelas eksperiment adalah 37,5 dengan nilai rata-rata 60.625. sedangkan hasil postestt dikelas kontrol mendapatkan nilai tertinggi sebesar 68.75 dan nilai terendah sebanyak 37.5 dengan nilai rata-rata 53.75 .

\section{PEMBAHASAN}

Metode penelitian ini memakai metode penelitian kuantitatif berbentuk quasy eksperiment. Hal pertama yang dilakukan dalam penelitian quasy eskperiment adalah mengukur kemampuan awal (pretest). Pretest dilakukan di dua kelas yang menjadi sampel adalah kelas eksperiment B 1 ,B 2 (kelas kontrol). Media diorama dipakai pada kelas eksperimen, sedangkan di kelas kontrol memakai kegiatan konvensional di TK. Kegunaan melakukan pretest adalah untuk untuk melihat kemampuan awal anak, denggan menggunakan item pertanyaan sebagai berikut : 1) anak mampu menggunting gambar yang sudah disediakan; 2) anak mampu mewarnai gambar yang sudah digunting; 3) anak mampu melem gambar yang sudah diwarnai; 4) anak mampu menempel gambar ke wadah yang sudah disediakan.

Hasil penilaian pretest dikelas eksperiment dan kontrol terhadap item-item pertanyaan, dengan rata-rata perkembangan kemampuan motorik halus berada pada taraf atau kriteria cukup di kelas eksperiment dan kontrol. Namun dibandikan kelas eksperiimen (B1) memiliki nilai yang lebih bagus dibandingkan B 2 (kelas kontrol). Agar mendapatkan simpulan dari hasil pretest, maka dilakukanuji hipotesisi berdasarkan uji hipotesiss yang telah dilakukan terdapat Thitung > Ttabel maka berarti $\mathrm{H}_{\mathrm{a}}$ di tolak dan $\mathrm{H}_{\mathrm{o}}$ di terima sehingga bisa disimpulkan pada pretest tidak berbeda yang signifikan antara kelas eksperiment dan kontrol dalam hal kemampuan motorik halus anak.

Setelah dilakukan pretest langkah selanjutnya yang diperbuat adalah melakukan treartment kepada kelas eksperiment sebanyak 3 kali dan dilanjutkan dengan melakukan posttest, begitu juga sebaliknya dikelas kontrol.

Selanjutnya hasil penilaian terhadap posttest dianalisis dengan menggunakan uji hipotesis yaitu dengan uji t-test. Berdasarkan uji hipotesis pada posttest $T_{\text {hitung }}>T_{\text {tabel }}$ ini berarti Ho ditolak dan Ha diterima dalam artian ada pengaruh penggunaan media diorama terhadap perkembangan motorik halus anak di Taman kanak-kanak Jannatul Ma'wa (Padang).

Umama (2016) mengatakan bahwa motorik halus ialah sebuah kemampuan yang dimiliki anak dalam mengontrol otot-otot kecil misalnya memunggut benda-benda mini dengan telunjuk dan ibu jari, memegang alat tulis menggunakan jemarinya untuk

mencoret, memindahkan benda-benda kecil dari satu wadah ke wadah lainnya menggunakan jermari tangan dan sebagainya. 
Adapun pengertian media dari Sadiman dkk dalam Kustiawan (2016 :6) yaitu media memiliki kegunaan untuk mengatasi keragaman latar belakang siswa. Media diorama adalah salah satu media 3 dimensi, dimana media diorama ini bisa menggambarkan suatu pemandangan, yang tidak bisa dibawah kekelas menjadi versi kecil nya dari suatu pemandangan tersebut.

\section{SIMPULAN}

Adapun kesimpulan dari penelitian yang peneliti lakukan adalah adanya perbedaan nilai rata-rata hasil kemampuan motorik halus anak di B 1 kelas eksperiment dimana kelas B1 lebih tinggi daripada kelas kontrol B2 di TK Jannatul Ma'wa Padang. Setelah dilakukan uji hipotesis menggunakan $\mathrm{t}$-test terlihat bahwa Thitug $>$ dari Ttabel Sehingga $\mathrm{H}_{\mathrm{a}}$ diterima dan $\mathrm{H}_{\mathrm{o}}$ tolak. Jadi ini membuktikan ada terdapat pengaruh penggunaan media diorama terhadap perkembangan kemampuan motorik halus anak di tk Jannatul Ma'wa (Padang).

\section{DAFTAR PUSTAKA}

Arikunto, Suharsimi. (2014). Prosedur penelitian suatu pendekatan praktik. Jakarta :PT Rineka Cipta.

Asmariani. (2016). “konsep media Pembelajaran PAUD”. Jurnal Al-afkar (Volume V no I)

Fardi, Hanan dkk. (2010). Silabus dan Hand out. Program PASCASARJANA : Universitas Negeri Padang.

Ismilasari, Yaashinta. (2013). Penggunaan Media Diorama Untuk Peningkatan Keterampilan Menulis Karangan narasi Pada Siswa Sekolah dasar. Jurnal PGSD (Volume 01 No 02).

Kustiawan, Usep. (2016). Pengembangan Media Pembelajaran Anak Usia Dini. Malang : Gunung Samudera.

Lestari, Maaswiyah. (2014). Peningkatan kemampuan Motorik Halus Melalui Media Diorama Pada Anak Kelompok A TK Marsudiswi Laweyan Surakarta Tahun ajaran 2013/2014.

Mursid. (2015). Belajar Pembelajaran PAUD. Bandung : PT Remaja Rosdakarya.

Ningsih, Andri. (2015). "identifikasi Perkembangan Keterampilan Motorik Halus Anak Dalam Berbagai Kegiatan Main di Kelompok B”. Jurnal PAUD (Edisi VII tahun Ke IV).

Noviasiam, Sri. (2012). "Pengaruh Bermain Menggunting Menempel Terhadap Kemampuan Motorik Halus Anak TK Bustanul Athfal Aisyiyah KarangAsem Tahun Ajaran 2011/2012”. Naskah Publikasi.

Peraturan Menteri Pendidikan dan Kebudayaan Republik Indonesia Nomor 137 Tahun 2014 Tentang Standar Pendidikan Anak Usia Dini.

Suwardi. (2011). "Efektivitas Media Pembelajaran Bagi Pendidik PAUD yang Ramah Lingkungan”. Jurnal AL-AZHAR INDONESIA SERI HUMONIORA. Volume I No II.

Umama. (2016). Pojok Bermain Anak Usia Dini. Yogyakarta : CV Diandra Prima Mitra Media. 